\title{
DINÂMICAS INFORMAIS DAS AGROINDÚSTRIAS FAMILIARES NO TERRITÓRIO: O CASO DO MUNICÍPIO DE SANTA CRUZ DO SUL - RS/BRASIL
}

\author{
INFORMAL DYNAMICS OF FAMILY AGRIBUSINESS IN A TERRITORY: \\ THE CASE OF THE MUNICIPALITY OF SANTA CRUZ DO SUL - \\ RS/BRAZIL
}

\author{
Erica Karnopp ${ }^{1}$ \\ Jaime Miguel Weber ${ }^{2}$
}

\begin{abstract}
Resumo
Este artigo teve por intuito analisar as condições concretas e contextuais que influenciam os agricultores familiares a "apostar" na informalidade dos processos agroindustriais. Uma das alternativas que vem sendo desenvolvida ao longo da história é o processamento de matérias-primas, especialmente de alimentos, que se constitui a partir do saber-fazer transmitido de geração a geração entre os agricultores familiares. Para a efetivação empírica desta pesquisa foi considerado o território de Santa Cruz do Sul. A pesquisa utilizou como método os pressupostos teóricos enraizados nas bases do materialismo histórico dialético. Desta forma, assinala conflitos e contradições das atividades informais de processamento de alimentos como uma relevante referência sociocultural e econômica para o território. Ademais, faz uma análise das exigências sanitárias e as tradições de produção, processamento, consumo e comercialização de alimentos. Foi possível verificar que a informalidade das agroindústrias familiares não é simplesmente uma situação transitória. $O$ que dá sustentabilidade, autonomia e viabilidade é o sistema de produção, de processamento da matéria prima e a comercialização diversificada, como estratégias de produção e reprodução das famílias. No contexto desta pesquisa, a informalidade se apresenta como resistência. Ela se manifesta como um fator de reflexão frente às transformações provocadas pelos mecanismos globais de dominação.
\end{abstract}

Palavras-chave: Agroindústrias Familiares Informais. Agricultura familiar. Feiras rurais. Legislação para agroindústrias.

\footnotetext{
Abstract

Its purpose was to analyze the concrete and contextual conditions that influence family farmers to "bet" on the informality of agriculture industry processes. One alternative that has been developed throughout history is the processing of raw materials, especially foods, which consists of the know how transmitted throughout the generations among family farmers. For the empiric confirmation of

${ }^{1}$ Doutora em Geografia pela Universität Tübingen-Alemanha. Professora da Universidade Santa Cruz do Sul (UNISC), Santa Cruz do Sul - RS, Brasil. E-mail: erica@unisc.br

${ }_{2}^{2}$ Doutorando em Desenvolvimento Regional pela Universidade Santa Cruz do Sul (UNISC). Bolsista CAPES. Santa Cruz do Sul - RS, Brasil. E-mail: jaimeweber1@hotmail.com
} 
this research, the territory of Santa Cruz do Sul was contemplated. The method used in the research consists of the theoretical assumptions rooted in the base of dialectic historical materialism. Thus, it presents conflicts and contradictions regarding informal foods processing activities as a relevant sociocultural and economical reference for the territory. Moreover, it analyzes the sanitary demands and the production traditions, processing, consumption and commercialization of foods in short commodity chains. It was found that the informality in family agriculture industries is not simply a transitory situation. It is the system of diversified production, processing of raw materials and commercialization that provides sustainability, as families' strategies of production and reproduction. In the context of this research, informality presents itself as resistance. It manifests as a factor to be thought over, in the face of the transformations caused by the global domination mechanisms.

Keywords: Informal family agriculture industries. Family Farming. Rural fairs. Legislation for agriculture industries.

\section{Introdução}

A presente pesquisa teve por intuito analisar a dinâmica da informalidade das agroindústrias familiares no contexto do território. Nesta pesquisa a agricultura familiar é entendida como uma categoria social de produção, inserida e reconhecida pela sociedade por suas contribuições materiais e imateriais.

É fundamental buscar a compreensão sobre como os atores sociais se mobilizam no território e como constroem as suas estratégias de vida e as distintas maneiras que enfrentam as dificuldades cotidianas. Em especial, a agricultura familiar tem sido aventada em muitos estudos como elemento de análise em função das consequências dos processos de reestruturação capitalista e da globalização dos mercados, bem como pela forte vulnerabilidade econômica e social a que vem sendo submetida.

A opção pela informalidade como prioridade para esta pesquisa justifica-se na medida em que se busca compreender esse universo que é tão significativo, ou seja, mais de $60 \%$ das agroindústrias existentes no território rural de Santa Cruz do Sul/RS são informais, e de certa forma invisíveis aos olhos do capital. Sendo assim, buscou-se compreender as estratégias sociais, econômicas e culturais, os significados, as motivações, as condições concretas e contextuais que influenciam os agricultores familiares a "apostarem" na informalidade de seus processos agroindustriais. Agroindústrias Familiares Rurais Informais (AFRIs) são compreendidas nesta pesquisa como aquelas geridas pelo grupo familiar, mas que não estão de acordo com todas as obrigações formais exigidas pelos órgãos competentes.

Nesse sentido, a opção de recorte territorial desta pesquisa foi realizada a partir das experiências de Agroindústrias Familiares Rurais Informais (AFRIS) existentes no território de Santa Cruz do Sul, que se localiza na região Centro Oriental do Estado do Rio Grande do Sul/Brasil.

As reflexões sobre a qualidade dos alimentos têm se tornado cada vez mais frequentes no cenário nacional e internacional, porque a alimentação tem uma relação direta com o bem-estar e a saúde das pessoas, além de possuir uma relação direta com o desenvolvimento dos territórios. Dessa forma, torna-se necessária a compreensão da atuação de algumas instituições públicas e entidades de assessoria, e os conflitos e contradições que se apresentam na relação com as agroindústrias familiares.

Nas últimas décadas, especialmente após os anos de 1990, essas atividades passaram a ter uma importância socioeconômica maior para as famílias, e também para as economias locais, especialmente pela forma descentralizada como se organizam. Segundo Kalnin (2004), foi a partir dos anos 1990 que os projetos de promoção da agricultura familiar passaram a apostar na implantação de agroindústrias como possibilidade de alternativa de renda e emprego, e melhoria das condições de vida dos agricultores.

Nesse contexto, as agroindústrias familiares têm encontrado um conjunto de limitações e contradições que passam pela produção, acesso a mercados e legislações com todas as suas exigências. As principais limitações enfrentadas são referentes à complexa e intensa burocracia para a adequação aos padrões sanitário, ambiental e produtivo. 
O desenvolvimento dos territórios abarca um conjunto de ações, e tende a colocar a centralidade nos temas econômicos, com vistas a desenvolver as atividades associadas a processos industriais e de serviços, com ênfase nas dinâmicas urbanas e na valorização da capacidade de produzir bens e serviços padronizados com custos reduzidos, utilizando-se de princípios de competitividade e de modelos com características homogeneizantes.

No espaço rural, essa lógica vem sendo introduzida desde os anos de 1950, com a implantação do modelo da modernização conservadora. Segundo Delgado (2012), uma das ações do projeto liberal para fortalecimento do agronegócio foi o incentivo através de políticas públicas para a agricultura voltada à exportação, com vistas à obtenção de superávits crescentes na balança comercial. Assim, vivenciam-se espaços e estratégias diferenciadas para o desenvolvimento das comunidades rurais, o agronegócio centrado na produção de commodities em grande escala, e a agricultura familiar focada na produção de alimentos, referenciada em escalas reduzidas, em diversificação da produção, e em cadeias curtas de comercialização.

A análise sobre o desenvolvimento de um determinado território requer o entendimento também sobre as estratégias de soberania e segurança alimentar, fomentando alternativas que possam a propiciar uma vida com qualidade e geração de renda, respeitando as especificidades e as heterogeneidades dos territórios e dos atores sociais, como ressalta a Abrandh (2013) sobre a necessidade de mobilização de diferentes setores da sociedade para a promoção da Segurança Alimentar e Nutricional. Buscar a compreensão do território em seu processo social e histórico, e com a relativização da concepção científica convencional e da racionalidade das legislações, tem se apresentado como uma temática e prática contraditória para vários atores imbricados nesses processos de desenvolvimento. É nesse contexto que se associa a reflexão sobre a alimentação e a qualidade dos alimentos que chegam à mesa do consumidor, numa perspectiva de conexão humana recriada entre os agricultores, os consumidores e as instituições.

\section{Procedimentos metodológicos}

Essa pesquisa se propôs a aprofundar a reflexão a partir de dados obtidos diretamente das Agroindústrias Familiares Informais, das organizações sociais e das instituições, para analisar as lógicas históricas e as questões que estão envolvidas nessa prática de resistência permeada por contradições pouco debatidas.

Utilizou-se como método de análise os pressupostos teóricos enraizados nas bases do materialismo histórico dialético como referência de análise e interpretação dos processos históricos de produção da agricultura familiar e seus conflitos sociais.

A aproximação com essas agroindústrias aconteceu a partir da definição do projeto de pesquisa. $O$ primeiro passo foi a observação das atividades nas feiras rurais para entender a dinâmica da comercialização. O segundo passo foi a aproximação com os feirantes através de conversas informais. Foi a fase mais delicada, porque a temática da informalidade cria certa situação de desconforto. Os agendamentos e as entrevistas aconteceram de forma aleatória com os agricultores. A coleta de informações se deu através de visitas nas propriedades e conversas no local da feira.

A realização das entrevistas foi efetivada por meio de um questionário semiestruturado com perguntas abertas e fechadas, para conhecer melhor a realidade e captar os limites, as contradições, e os motivos que justificam a permanência dessas agroindústrias na informalidade. Nove agricultores foram entrevistados.

Em relação às entidades privadas e instituições públicas, o critério de escolha foi de priorizar aquelas que possuem maior aproximação com os agricultores e com as feiras rurais. Não houve intencionalidade em identificar "culpados" nesse processo, a busca maior foi em relação às alegações confusas e contraditórias que levam as instituições a "pressionar" as AFRIs para formalização.

\section{Agricultura Familiar e produção de alimentos}

Os conceitos e as caracterizações que fazem parte da reflexão dessa pesquisa buscam contribuir para o entendimento do contexto da produção de alimentos, de suas contradições, e das relações de poder que estão imbricadas em distintos cenários, com o olhar centrado na agricultura familiar e suas atividades de processamento informal. 
No mesmo ritmo em que se acentuava a implementação da modernização da agricultura, a prática da agricultura foi extrapolando as suas capacidades produtivas naturais com a artificialização do ambiente e a simplificação dos sistemas de produção. Para Santos (2003, p. 93), "[...] o território é usado a partir de seus acréscimos de ciência e técnica, e tais características o definem como um novo meio geográfico". Nesse contexto, muitos sistemas de produção inerentes à agricultura familiar foram sendo desestruturados e componentes dos recursos naturais foram se degradando e comprometendo, em parte, as economias e os saberes locais.

Assim, o processamento de alimentos possui uma função relevante, tanto para o autoconsumo como para esses mercados locais, a partir da possibilidade de ampliação da conservação dos alimentos. Goodman (2003) aponta que há uma tendência de contraposição ao atual modelo de produção e consumo em massa e às cadeias alimentares longas, típicas da economia globalizada.

$\mathrm{Na}$ agricultura, a prática da informalidade possui uma gama de experiências que foram se constituindo empiricamente à margem dos processos formais das relações campo-cidade. Foi em meados de 1970 que o termo setor informal passou a ser visualizado de forma mais analítica. Para Theodoro (2000), a Organização Internacional do Trabalho (OIT) é que passou a tratar o conceito de setor informal como um novo instrumento explicativo para uma prática secular, que consistia em atividades econômicas de baixa produtividade e que se desenvolviam sem atender os preceitos legais, e ocupavam espaços marginais do mercado.

Essas práticas compõem um legado de conhecimento identificado por muitos autores como o saber-fazer. Brandão (2015, p. 16) identifica como conhecimento tradicional, e que se constitui num amplo indicador do nível de evolução cultural do homem com o ambiente, e a geração de conhecimento acontece através dessa interação com base em processos sucessivos e dinâmicos. Nesse sentido, a agroindústria informal possui uma relação com o conhecimento tradicional e traz à tona a possibilidade e a necessidade de se buscar um diálogo de igual para igual, entre os atores sociais.

\section{A Agroindústria Familiar: uma estratégia de resistência}

Com frequência, os agricultores familiares recorrem a práticas de processamento de produtos a fim de agregar valor a sua produção. Segundo a base de dados do Programa Estadual de Agroindústria Familiar (PEAF), em 2013 estavam cadastradas 1.439 agroindústrias familiares no Rio Grande do Sul. Essas atividades de processamento, normalmente passam a ter uma relação com as entidades e instituições, para o suporte burocrático ou para assessoria técnica. Gazolla (2009) comenta sobre a carência de motivação que as organizações de agricultores têm em relação às instituições formais, considerando que muitas dessas organizações de agricultores possuem preferência em se manter na informalidade, enquanto que as instituições formais buscam integrar essas organizações aos padrões formais para o processamento de alimentos.

Nesta pesquisa, as agroindústrias que não estão totalmente de acordo com os preceitos legais são identificadas como informais. Sabe-se que são utilizados outros termos para caracterizar essas agroindústrias, como ilegais, clandestinas, entre outros. Para Wilkinson e Mior (1999), é necessário fazer uma distinção entre o informal e o ilegal pelo fato de seus produtos não serem proibidos. Tratase de uma atividade cujos processos de produção não estão totalmente de acordo com os padrões vigentes. Compreender a informalidade dessas atividades, a partir das limitações e contradições existentes entre os agricultores, organizações e instituições formais, torna-se relevante no sentido de entender as tendências e possibilidades futuras da agricultura familiar, numa perspectiva de desenvolvimento regional.

Para Schneider (2010, p. 121), a transformação nas unidades produtivas está relacionada ao conjunto de estratégias que interferem em aumento ou diminuição do grau de dependência aos mercados.

Nesse sentido, o processamento de alimentos em pequenas agroindústrias tem se tornado uma importante estratégia para a agricultura familiar, como é o caso das AFRIs do município de Santa Cruz do Sul. Para Gazolla (2009), os pequenos empreendimentos agroindustriais têm uma importância crescente em algumas regiões onde predomina a agricultura familiar. No entanto, as agroindústrias familiares têm encontrado um conjunto de barreiras legais, como aponta Guimarães (2001), ao considerar que as normativas sanitárias apresentam uma série de empecilhos, e que se pode notar pelo elevado percentual de informalidade desse setor. 
Segundo as informações da Emater/RS (2019), o número de agroindústrias familiares que estão cadastradas no PEAF/RS ultrapassa a 3.500 unidades, e pouco mais de 1.500 dessas agroindústrias estão formalizadas. Isso demonstra a importância de se analisar esse cenário, os seus significados, as suas contradições e motivações.

A agricultura familiar possui uma relação direta com o tema das políticas públicas de Estado e de governo, com a criação e implantação do SUASA (Sistema Unificado de Atenção a Sanidade Animal), especialmente a partir da regulamentação da lei através do decreto $\mathrm{n}^{\circ} 5.741$ de março de 2006, e no Rio Grande do Sul com a aprovação da Lei no 13.825 de 08 de novembro d 2011 de criação do SUSAF (Sistema Unificado Estadual de Sanidade Agroindustrial Familiar, Artesanal e de Pequeno Porte), regulamentada em 2012. Estes dois sistemas, SUASA e SUSAF, estabelecem a base legal para os municípios que queiram implantar a equivalência sanitária dos serviços de inspeção municipal (SIM), possibilitando a comercialização dos produtos para além das fronteiras municipais.

Dessa forma, esses sistemas se apresentam como modelos científicos "legitimados pela sociedade", sem apresentar uma alternativa de coexistência para situações que não estão contempladas nesses modelos tradicionais. Para Setton (2002, p. 69), "a coexistência pode se configurar em um campo híbrido e diversificado de códigos e arquétipos identitários, consolidandose num processo de socialização moderna baseado em variados padrões de referência".

Portanto, o foco dessa pesquisa buscou elementos teóricos sobre a temática da alimentação para subsidiar a reflexão sobre as contradições existentes nos modelos em curso na sociedade e situações empíricas referenciadas em práticas concretas vivenciadas por agricultores familiares do território de Santa Cruz do Sul/RS.

\section{Dinâmicas Informais das AFRIs no Território de Santa Cruz do Sul}

O município de Santa Cruz do Sul está localizado no centro do Estado do Rio Grande do Sul, à $155 \mathrm{~km}$ de Porto Alegre. Segundo dados do IBGE (2017), a área de unidade territorial do município é de $733,409 \mathrm{~km}^{2}$. A estimativa populacional para o ano de 2019 era ultrapassar 130 mil pessoas. De acordo com informações da Secretaria de Agricultura o município conta com 06 agroindústrias e 02 associações formalizadas que comercializam seus produtos nas feiras do município. Além dessas, há mais 07 agroindústrias certificadas no município que não comercializam seus produtos nas feiras.

Atualmente, o município conta com aproximadamente 22 agroindústrias informais que comercializam nas feiras, e mais 04 que não comercializam nas feiras. Considerando apenas as agroindústrias e associações que possuem algum tipo de vínculo com o município, percebe-se que de um total de 41 agroindústrias, mais da metade não estão formalizadas.

O recorte municipal de Santa Cruz do Sul/RS, nesta pesquisa, caracteriza-se como um território, porque apresenta enredamentos permeados por relações de poder erigidas ao longo do tempo. Segundo Santos (2004, p.47), "o território é o chão e mais a população, isto é, uma identidade, o fato e o sentimento de pertencer àquilo que nos pertence. O território é a base do trabalho, da residência, das trocas materiais e espirituais e da vida, sobre os quais ele influi".

A análise de agroindústrias informais desse território é a busca pelo entendimento desses agricultores que optam pela informalidade de suas atividades de processamento de alimentos e que não são "reconhecidos" por não se submeterem a uma legislação que não lhes convêm. Para Weisheimer (2013), a invisibilidade, do ponto de vista social, refere-se a circunstâncias em que determinados sujeitos se encontram imperceptíveis ou invisíveis nas relações sociais de seu território, como uma ação social que sugere não ver o outro, a sua existência social e o que se relaciona a essa existência. Assim, fica evidente que há um impasse para ser equacionado e que se desdobra em vários elementos e contradições que foram sendo analisadas a partir da pesquisa de campo.

Assim, a informalidade do processamento de alimentos será analisada a partir da análise das entrevistas realizadas com os agricultores familiares informais.

Para preservar a identidade serão utilizadas as siglas AFRI e E numeradas, para identificar os agricultores e os representantes das instituições entrevistadas, respectivamente.

\section{Discussão dos resultados}

Para além dos aspectos econômicos das AFRIs, essas experiências representam um exercício de gestão autônoma com participação na economia local e contribuem para o desenvolvimento do 
território. Para Schumpeter (1997), o significado do processo econômico como o funcionamento de seu mecanismo ou organismo em um dado estágio de desenvolvimento pode ter distintos motivos, mas o significado é sempre a satisfação de necessidades.

Dessa forma, a satisfação de necessidades nesse tipo de atividade econômica transcende os aspectos mercadológicos. Os aspectos socioculturais se manifestam a partir das relações de pertencimento e de protagonismo estabelecidas nesse espaço.

\section{Figura 1 - Identificação das agroindústrias informais pesquisadas}

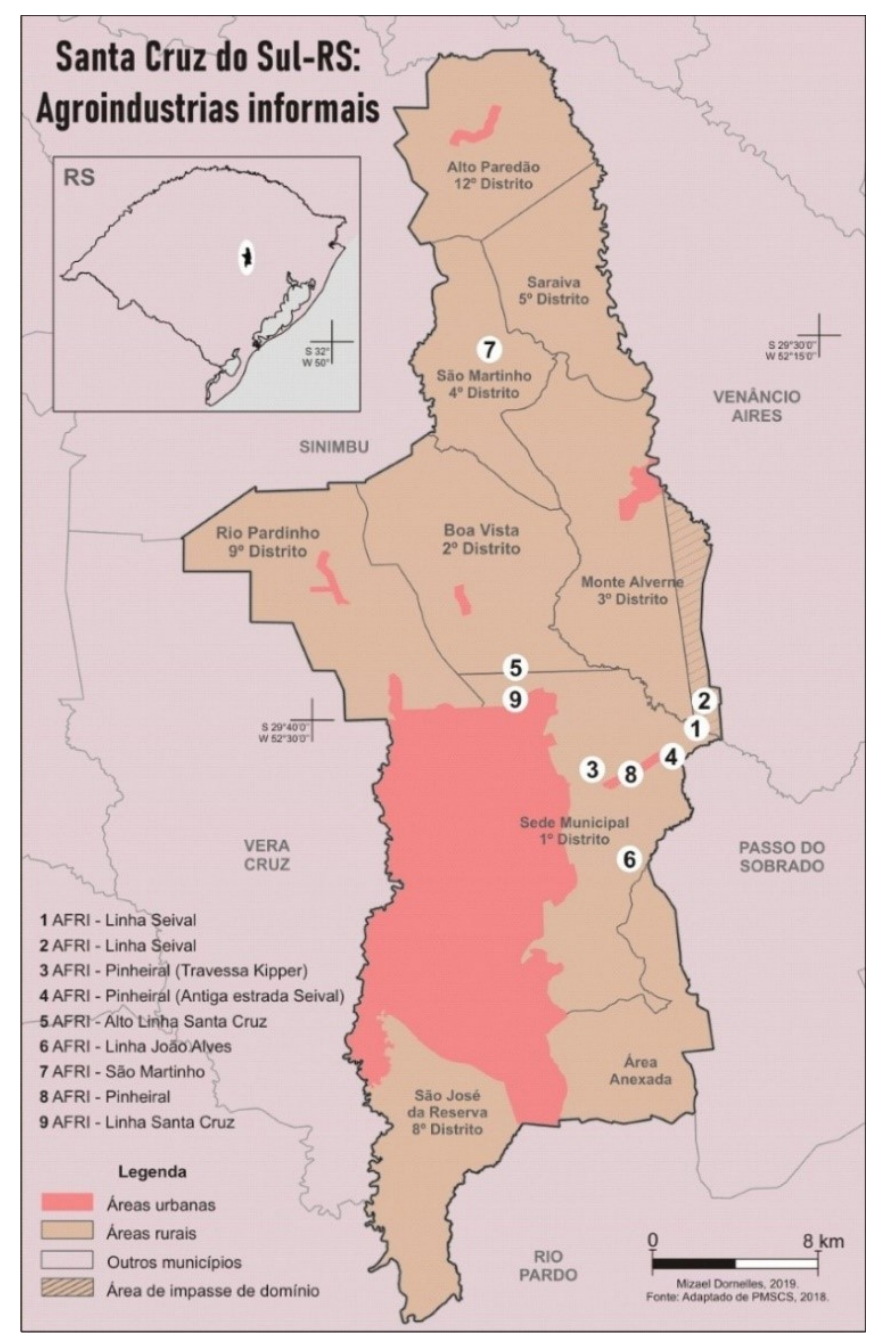

Fonte: Prefeitura Municipal de Santa Cruz do Sul, 2015. Elaboração/adaptação: WEBER (2019).

Nas agroindústrias visitadas, as entrevistas revelaram que há forte influência e participação da família no processo de manutenção dessas agroindústrias e que a gestão é realizada de forma compartilhada. Essas características são confirmadas por MIOR (2005), ao afirmar que a agroindústria familiar rural possui uma configuração em que a família rural produz, processa e/ou transforma parte de sua produção agrícola e/ou pecuária, buscando, sobretudo, a produção de valor de troca que se realiza na comercialização.

Há predominância das mulheres nas atividades de processamento analisadas nessa pesquisa e o controle é realizado pelas pessoas mais idosas que possuem o conhecimento (saber-fazer) como herança das famílias. A idade das nove pessoas que participaram das entrevistas varia entre 47 e 70 anos, sendo que a maioria possui idade superior a 60 anos. Algumas já estão aposentadas, e outras estão muito próximas da aposentadoria. Contudo, a opção pela permanência no meio rural tem muito a ver com o modo e a qualidade de vida, assim como destacam Winckler, Boufleuer, Ferreti e De Sá (2016, p. 191) ao ponderar que os hábitos de vida e a cultura da sua região influenciam o perfil de idosos do meio rural e que as atividades mais tranquilas do cotidiano podem se apresentar como elementos importantes para um envelhecimento saudável, comparadas com as atividades urbanas. 
De acordo com o IBGE, Censo Agropecuário de 2017, o percentual de produtores com mais de 65 anos aumentou de 18\% para 23\%, nos últimos 11 anos. Assim, a população rural está envelhecendo e o número de pessoas ocupadas nos estabelecimentos rurais está diminuindo.

A perspectiva ou a necessidade da formalização das agroindústrias familiares rurais diminui a probabilidade de continuidade dessa atividade, segundo os entrevistados. Para Abramovay (1998), a sucessão na agricultura familiar envolve mais do que a continuidade das propriedades, a sucessão rural envolve o destino de várias regiões devido ao forte papel social e cultural desempenhado pela agricultura familiar.

Outra questão que chama a atenção é a formação escolar, das nove pessoas entrevistadas, sete possuem ensino básico e duas concluíram o ensino superior, e a outra se mantém na propriedade por questões familiares. Assim, a baixa escolaridade e a idade avançada se apresentam como limites significativos para uma possível ou necessária mudança no modo de vida e/ou opção de trabalho.

\section{Características socioeconômicas das agroindústrias familiares informais}

As unidades familiares que foram analisadas nesta pesquisa são constituídas de pequenas propriedades que não ultrapassam um módulo fiscal rural, conforme a Lei $\mathrm{n}^{0}$ 8.629/1993, Art. 4, incisos II e III. A mão de obra é preponderantemente familiar, e as atividades são bastante diversificadas, típicas da cultura regional.

A definição da atividade de processamento de alimentos foi uma das primeiras dificuldades enfrentadas nas entrevistas. A estratégia se concentra em um conjunto de produtos que fazem parte do sistema de produção. Para Bianchini (2015), na agricultura familiar o processamento de alimentos é utilizado para constituir ainda mais um mix de produtos que passam a compor um portfólio e tramitar nos mercados locais e regionais, tratando-se de complementariedade entre uma atividade e outra.

Os entrevistados afirmam que houve incentivo das instituições para a produção diversificada e para o processamento de alimentos. A avaliação do entrevistado AFRI 3 é que no início foi muito tranquilo, mas na medida em que se tornou um negócio interessante, apareceu a fiscalização pressionando para a formalização das agroindústrias e a escolha de um produto para o processamento.

Esse fato reforça que a viabilidade não está apenas em um ou dois produtos. O Ministério do Desenvolvimento Social e Combate à Fome (MDS, 2014) reforçava a ideia de que a agricultura familiar é como "uma forma de produção onde predomina a interação entre gestão e trabalho; são os agricultores familiares que dirigem o processo produtivo, dando ênfase na diversificação e utilizando o trabalho familiar". Neste contexto, percebe-se certa contradição das entidades e instituições de apoio e assessoria; por um lado há o fomento para a diversificação e o processamento de alimentos, por outro lado há a pressão para a formalização que se apresenta como certa indução à especialização da produção.

Nas agroindústrias que fazem parte desta pesquisa, o tempo de funcionamento das atividades de processamento varia entre 12 e 40 anos. Mudar essa lógica sem que haja uma justificativa plausível não tem entendimento e nem concordância por parte desses agricultores.

Em todos os casos entrevistados, as atividades foram apreendidas ou possuem influência dos familiares e é evidente a preocupação em manter alguns princípios do processamento, como por exemplo, evitar o uso de conservantes para poder consumir e oferecer produtos que preservem atributos naturais como sabor e aroma da matéria-prima. Para o entrevistado AFRI 6 "manter o gosto da fruta no produto processado tem alguns segredos. Às vezes, para a manutenção do gosto da fruta acentuado se coloca a casca da fruta, parte ou toda a casca, depende da fruta". A busca por informações também é salientada pelo entrevistado AFRI 6, "queremos fazer coisas novas e experimentar novos processos". Então, há uma associação do conhecimento empírico - saber fazer - com o conhecimento científico. A questão central é a qualidade sanitária dos produtos e isto é perfeitamente compatível e aceitável pelos agricultores entrevistados.

Nesse sentido, o Relatório da Subcomissão das Agroindústrias Familiares da Comissão de Agricultura, pecuária e Cooperativismo da Assembleia Legislativa (RDI 87/2017) aponta para a preocupação com a atual legislação para as agroindústrias. A partir deste Relatório, pode-se observar um conjunto de questões cruciais para as agroindústrias familiares numa perspectiva de desenvolvimento territorial, permeadas por distintos interesses e contradições.

Do total de entrevistados, oito possuem infraestruturas específicas e apenas um realiza o processamento junto às atividades da residência. As estruturas existentes nas propriedades são 
bastante diversas, porque normalmente são aproveitados os recursos materiais e as adaptações são realizadas de acordo com a facilidade operacional e os tipos de produtos. O entrevistado AFRI 7 ressalta que é inviável seguir todas as regras ao afirmar que "do jeito que eles querem não tem como eu legalizar (formalizar) todos os produtos".

Assim, percebe-se que a formalização não se traduz apenas em estrutura física, também afeta um conjunto de questões socioculturais e econômicas. Há uma legislação e um modelo para cada tipo de processamento, mas para esses agricultores esses modelos nem sempre se adequam às realidades das propriedades. "Estamos cansados de que eles venham dizer que o que fazemos está errado", comenta o entrevistado AFRI 7.

Esse tipo de alerta deve servir para sensibilizar as partes envolvidas nas atividades de processamento e de fiscalização (poder público), porque essas agroindústrias estão inseridas nas economias dos territórios. Para Schneider e Grisa (2008), a produção para o consumo contempla as necessidades alimentares das famílias, contudo, alguns alimentos que não são produzidos pela família são buscados fora da propriedade.

Sobre o faturamento bruto das agroindústrias, a pesquisa demonstra que é bastante variado e também depende do tipo de produto que é processado e da origem da matéria prima, em função da relação com o custo de produção. Então, há de se considerar que a comercialização na feira envolve outros produtos do sistema de produção, e que também passam por processamento na propriedade. Para analisar a renda bruta necessitaria de uma imersão no sistema de produção, com uma metodologia específica que pudesse dar conta das partes e do todo que envolvem a produção e o processamento.

Não se pode deixar de mencionar que nos valores da renda bruta não estão incluídos os produtos que são consumidos pelas famílias - o autoconsumo. Como destacam Schneider e Grisa (2008) que com a produção de alimentos para o autoconsumo há uma economia da família que deixa de gastar com a compra de alimentos - equivalente em moeda - nos supermercados.

No que se refere às estruturas e equipamentos, o capital utilizado para o processamento de alimentos das AFRIs desse estudo é de origem própria para a maioria das agroindústrias. Ficam explícitas as posições contrárias a financiamentos, com o claro intuito de não contraírem dívidas.

Isso demonstra que as simplificações propostas, como no Programa para Agroindústria Familiar, não proporcionaram uma ruptura em relação ao modelo preconizado, no sentido de "tratar os diferentes como diferentes". No que se refere ao destino dos produtos, os dados desta pesquisa mostram que mais de $90 \%$ do que é processado é para o comércio, tanto nas feiras com em roteiros locais ou sob encomendas. Os entrevistados afirmam que possuem uma clientela que mantém uma relação de fidelidade. $\mathrm{O}$ entrevistado AFRI 4 comenta que "na feira tu já tem os clientes certos para determinados produtos, tem clientes de mais de vinte anos". Essa relação de comércio de proximidade - olho no olho - tem um significado importante, tanto para o produtor como para o consumidor.

No que se refere aos volumes de produção e processamento, os agricultores desta pesquisa afirmam que não têm tido variações significativas ao longo dos anos e não há interesse em aumentar esses volumes. Essa questão se apresenta como uma contradição porque, de certa forma, a formalização "força" o aumento da produção, e isso reflete na lógica de produção construída pela família.

Tabela: Fatores que restringem o aumento da produção

\begin{tabular}{l|l}
\hline Fatores que restringem o aumento da produção* & $\mathrm{N}^{\circ}$ de AFRIs \\
\hline Capital para investimento & 4 \\
\hline Mão de obra & 1 \\
\hline Mercado saturado & 1 \\
\hline A legislação dificulta & 8 \\
\hline Outras: área de terra para plantio; idade avançada. & 2 \\
\hline
\end{tabular}

Fonte: Dados da pesquisa, 2018/19. WEBER (2019).

*Cada agricultor poderia optar por até dois fatores.

Percebe-se que a legislação é colocada como um fator preponderante de limitação, como pondera o entrevistado AFRI 4 "a legislação é o que mais me preocupa. Para mim (sic) legalizar eu preciso de estrutura que eu não tenho, se eu plantar mais eu tenho que ter alguém para fazer”. Nesse caso, o agricultor conjuga dois fatores, a falta de estrutura adequada, e o limite da mão de obra na 
propriedade. "Eu estou vendo que ali na frente a legislação vai dificultar a continuidade, por isso eu não quero investir", comenta o entrevistado AFRI 7.

A opção por esse modo de vida transcende a questão econômica de acumulação de capital, tem muito mais a ver com um jeito de viver que possibilita a esses agricultores um estilo de vida com qualidade, com autonomia, com controle do seu negócio e com a segurança alimentar da família e dos consumidores.

\section{Processos e estratégias de comercialização das agroindústrias familiares informais}

O que esta pesquisa procura sublinhar é que a informalidade é uma opção consciente para viabilizar a permanência na atividade da produção agropecuária. No caso dos feirantes, a comercialização é realizada entre um a três dias por semana, numa ou em mais feiras rurais, localizadas em pontos distintos do espaço urbano.

"Produzir para sobreviver" pode ser uma boa síntese daquilo que esse tipo de agricultor almeja, ou seja, manter o seu jeito de produzir, processar e comercializar, como aponta o entrevistado AFRI 8 ao afirmar que pretende continuar processando do seu jeito, a menos que seja impedido pela vigilância sanitária. Para esses agricultores a formalização não é viável. Isso não significa que a formalização não serve para ninguém, de forma alguma. Para muitos agricultores a informalidade representa transitoriedade.

Em geral, os preços dos produtos praticados são menores do que os preços dos produtos convencionais similares, para os agricultores que fazem parte desta pesquisa.

Os agricultores entrevistados manifestaram seu desconforto em relação à comparação sobre a qualidade, consideram os seus produtos superiores e incomparáveis. Uma das justificativas é a não utilização de vários insumos químicos artificiais permitidos e orientados pela legislação, utilizados pelas indústrias convencionais.

Em relação ao uso de rótulo nos produtos, os entrevistados afirmam que a opção de não colocar rótulo também é considerada como uma vantagem porque eles sabem que o consumidor procura na feira justamente os produtos diferenciados. É interessante a observação feita pela assistência técnica sobre a rotulagem dos produtos, a partir da observação e das falas dos próprios agricultores. O entrevistado E1 diz que, de forma geral, o consumidor associa o produto com rótulo como sendo industrial e o produto sem rótulo como sendo colonial.

$\mathrm{O}$ rótulo para esses agricultores não tem relação com a intencionalidade de omitir informações sobre a composição dos produtos, mas, curiosamente, tem a ver com uma questão de marketing no que se refere à diferenciação de seus produtos.

\section{Perspectivas para as agroindústrias familiares informais}

De acordo com as entrevistas realizadas nesta pesquisa, a perspectiva para a continuidade da atividade de processamento para essas AFRIs é bastante "nebulosa", em consequência dos conflitos e contradições que estão presentes nesse campo de disputas e de interesses. O entrevistado AFRI 9 diz que são poucas as perspectivas para os próximos anos: "porque se é para fazer agroindústria (formalizar) não adianta. Isso não adianta, eu não posso usar o meu produto". 0 entrevistado AFRI 7 afirma que não se trata de uma simples opção, ao comentar que "não é que eu não queira, a pergunta (desafio) que eu fiz para a Secretaria da Agricultura: eu quero que me levem para uma agroindústria que se regularizou nos últimos três anos e que está indo bem". Enfim, dos nove agricultores entrevistados apenas um aponta para a possibilidade de talvez investir na formalização.

Percebe-se que não se trata apenas de uma transgressão à legislação vigente. A proposta de formalização é percebida como uma contradição, porque não leva em conta realidade desses agricultores. Além disso, eles apontam que nem sempre os procedimentos são padronizados, em alguns casos são contraditórios em função da interpretação da lei, e outros, em função da falta de bom senso.

O entrevistado AFRI 7 diz que cancelará a atividade de processamento, caso haja obrigatoriedade para a formalização: "Nem tanto pela burocracia, mas pela incomodação, por exemplo, se tu te legaliza hoje, amanhã a fiscalização está batendo e dizendo: isso ali está errado, vamos ter que fazer assim... nesse sentido".

Sobre o significado da formalização das agroindústrias o entrevistado AFRI 1 faz uma síntese: “é um processo que já se inicia cansando, pela burocracia”. Os agricultores em nenhum momento 
negam a importância de ter um regramento. O entrevistado AFRI 8, faz uma análise do tempo de feira e a inexistência de problemas relacionados com qualquer risco de saúde pública. Assim, a informalidade não é só temor com o "novo", mas uma opção de resistência.

De fato, em relação ao que os agricultores pensam sobre a legislação para as agroindústrias os comentários são bem variados. O entrevistado AFRI 1 diz que há muita burocracia e poucos incentivos, muitas exigências e poucas soluções. O entrevistado AFRI 2 pondera que a legislação para a agroindústria familiar é inadequada e mais fiscalizadora e punitiva do que de apoio. Pereira e Botelho (2017) apontam algumas contradições entre as normas e a realidade do cidadão ao considerar que há certa indução para se acreditar que a falta de efetividade da norma é em função da conduta dos destinatários. Contudo, é fundamental que esteja ajustada com a realidade socioeconômica do destinatário, para que seja reconhecida e cumprida.

Esta pesquisa evidenciou que os agricultores familiares não conhecem bem a legislação para as agroindústrias, ainda que sejam diretamente abrangidos. Para Pereira e Botelho (2017, p. 117), "assim, questiona-se, cada vez mais, a legitimidade da norma, ou seja, mais importante do que o procedimento de elaboração, são os fundamentos da norma, a sua interpretação e a sua aplicação".

A partir da fala dos agricultores, a aproximação das instituições é sempre no sentido de "motivar" a formalização e o apoio concreto para as agroindústrias informais é bastante restrito. Para o entrevistado AFRI 1, o poder público "só sabe dizer o que deve ser feito".

A Emater realiza oficialmente o trabalho de extensão rural e social nos municípios, por isto é perfeitamente compreensível que a empresa direcione sua ação no sentido de apoiar a formalização das agroindústrias. Nem por isso é descartada a assessoria para as agroindústrias informais, como pondera o E1 "nós conhecemos muitos produtores, nós visitamos muitas propriedades que processam informalmente". O E1 considera que o tema da formalidade e da informalidade é bastante complexo: “... quando se cai na escala de produção de uma agroindústria formal há que se ter uma durabilidade maior de prateleira, aí se obriga muitas vezes a usar alguns conservantes, e assim por diante”. Acrescenta ainda, a importância da qualidade biológica e nutricional dos produtos sem conservantes e a importância de fomentar as cadeias curtas que comercializam produtos frescos que não necessitam permanecer em prateleiras.

Sendo assim, a discussão sobre a qualidade dos alimentos processados deveria passar por uma avaliação, e quem sabe por uma nova análise e conceituação.

Conforme a fala do E2, os benefícios do poder público estão voltados para quem está formalizado ou pretende se formalizar e que a informalidade propóe o comércio clandestino, com a venda direta ao consumidor.

Os agricultores que participaram desta pesquisa não possuem a intenção de esconder suas atividades de processamento, tanto é que os seus produtos são comercializados pelos próprios agricultores nas feiras rurais que são espaços públicos. Percebe-se na fala do E2 que, ao mesmo tempo em que fala em clandestinidade, há um reconhecimento sobre as dificuldades para formalização, "é limitante, ela é problemática porque existe um conceito de que a legislação brasileira ela é feita para impedir que o pequeno se estabeleça, ela é feita para o grande e é cobrada a mesma coisa que é cobrada para um empreendimento grande". Para o caso do processamento de produtos de origem animal, a legislação é bem mais rígida em função das probabilidades maiores de contaminação dos produtos.

Desse modo, o E1 lembra que, se a questão é a qualidade biológica e nutricional dos produtos processados, há que se definir como aferir essa qualidade, porque se pode averiguar facilmente a qualidade do produto através de análise laboratorial. O entrevistado AFRI 4 comenta sobre a qualidade dos produtos com uma consideração relevante: "olha, para dizer francamente, até hoje não teve nenhuma queixa de ninguém, em relação a algum produto estragado ou coisa assim. Então, o que leva um consumidor a comprar determinados produtos nessas condições possui uma relação direta com a qualidade.

Percebe-se que os preços praticados nas feiras oscilam quando comparados com produtos convencionais, e segundo os entrevistados os preços ajudam, mas é a qualidade (gosto, sabor, aroma, e ausência de conservantes) do produto que garante a fidelidade dos consumidores. E nesses casos a durabilidade (validade) do produto não é um fator preponderante como nos mercados convencionais.

Para o entrevistado AFRI 6 a qualidade de vida é fundamental: "eu quero a minha qualidade de vida, por isso eu faço o melhor produto". Comenta que passaram a produzir tudo o eles possuem condições de produzir, e evitar ao máximo a compra e o consumo de produtos industrializados 
convencionais. O entrevistado AFRI 7 considera que a qualidade dos seus produtos é boa, porque não usa conservantes em nenhum produto. Nesses casos, a partir da percepção desse agricultor, a qualidade do produto se apresenta como uma contradição em relação ao que está desenhado pela legislação. Segundo Scarabelot e Schneider (2012) novos critérios e exigências estão aparecendo em relação à qualidade dos alimentos:

[...] uma análise contemporânea do consumo reivindica considerar o perfil de uma sociedade que emerge com novas exigências. Hoje consumidores começam a exercitar sua cidadania e reflexividade estabelecendo critérios e exigências em relação ao consumo de alimentos onde à qualidade passa a ser definida com base no conhecimento e na proximidade e não mais somente em critérios normativos ou legais (SCARABELOT; SCHNEIDER, 2012. p. 111).

Isso demonstra que há uma preocupação do consumidor e que a garantia de um alimento saudável não se dá apenas pelo atendimento às normas. A relação de confiança com o consumidor o olho no olho - é considerado um aspecto relevante.

A partir de todas essas argumentações, percebe-se certa angústia quanto à possibilidade concreta de que tudo o que foi construído (saber-fazer) durante décadas pode ser inviabilizado de uma hora para outra.

O Quadro 1 apresenta uma breve síntese das principais contradições entre o que é apresentado pelas instituições/entidades, como proposições externas, e o que os agricultores (AFRIs) vislumbram como estratégias de sobrevivência e de resistência.

Quadro 1: Contradições em relação às atividades de processamento de alimentos

\begin{tabular}{|l|l|l|}
\hline Questões envolvidas & Proposições externas & Agroindústrias informais \\
\hline Formalização & Estímulo (pressão) & Sem interesse (inviável) \\
\hline Aumento da produção & Estímulo & Sem interesse e condições \\
\hline Aumento do processamento & Estímulo & Sem interesse e condições \\
\hline Abrangência de mercado & Estímulo & Sem interesse \\
\hline Diversificação & Estímulo (discurso) & Manter ou aumentar \\
\hline Sustentabilidade & Estímulo (discurso) & Própria da agricultura familiar \\
\hline Sistema de produção & Pouco conhecimento & Próprio da agricultura familiar \\
\hline Renda & Estímulo para aumento & Satisfação com a situação \\
\hline Qualidade & Conceitos confusos & Satisfação \\
\hline
\end{tabular}

A orientação é relativamente clara, ou formaliza e continua comercializando na feira, ou cessa a comercialização.

Essas questões que buscam conhecer e entender a angústia dos proprietários das AFRIs sobre a qualidade de seus produtos apresentam um conjunto de elementos que possibilitam uma compreensão mais clara e transparente sobre os dilemas, dúvidas e contradições. Há que se destacar que em nenhum momento das entrevistas houve qualquer tentativa de culpabilidade de pessoas ou de instituições. Existe o entendimento do papel das instituições em "seguir a lei", mas as manifestações são no sentido da não compreensão da lei e da forma como está sendo proposta ou imposta a sua aplicação.

De certa forma, essas experiências informais de produção e processamento de alimentos são também sistemas alimentares resilientes, sustentáveis, seguros, e com razoável diversidade de alimentos saudáveis para as famílias, numa prática que minimiza o desperdício e os problemas ambientais.

Em nível mundial também há uma crescente preocupação com a segurança alimentar e com as questões ambientais. Pode-se citar o Slow Food (comida lenta, em inglês) que é uma organização não governamental que, além de seus nobres objetivos, é também um movimento que se opõe à tendência de padronização do alimento no Mundo, e defende a necessidade de que os consumidores estejam bem informados, tornando-se coprodutores. Para esse movimento o alimento que comemos deve ter bom sabor; deve ser cultivado de maneira limpa, sem prejudicar nossa saúde, o meio ambiente ou os animais; e os produtores devem receber o que é justo pelo seu trabalho. Tomando 
como referência essa tendência mundial, pode-se muito bem dizer que as agroindústrias familiares informais estão muito mais em consonância com essa tendência do que os modelos agroindustriais convencionais.

Para isso, precisam ser percebidos e compreendidos como produto social e histórico do território, com as particularidades e especificidades de um contexto que vai além da análise economicista e financeira inerente a empreendimentos econômicos de médio e grande porte.

\section{Considerações finais}

A informalidade nesta pesquisa não se apresenta somente como uma resistência a um modelo ou a uma legislação, existe uma bagagem cultural envolvida nesses processos informais de processamento de alimentos. Neste tema da informalidade há uma série de contradições que implicam em relações de poder. A complexidade é bem maior do que aparece nos debates porque se trata de um tipo de agricultor familiar que produz e processa alimento, possui uma relação harmônica com o ambiente e com a biodiversidade, mantém a produção sistêmica, possui alto grau de resiliência, faz parte da economia do território e, fundamentalmente, preserva a sua cultura a partir dos saberes tradicionais, produzindo conhecimento.

Esse tipo de agricultor familiar referenciado nesta pesquisa possui uma relação direta com vários dos Objetivos do Desenvolvimento Sustentável (ODS) em função dos temas da segurança alimentar, a preservação ambiental, as questões de saúde e bem-estar, consumo e produção sustentáveis, entre outros. A inviabilização dessa forma de produzir e processar alimentos vai à contramão do que se vislumbra para as pessoas, para o planeta e para a prosperidade.

Nesta pesquisa foi possível verificar que a informalidade das agroindústrias familiares não é simplesmente uma situação transitória, como é apontada em alguns estudos. O que reforça essa afirmação é que o tempo de funcionamento das atividades de processamento varia entre 12 e 40 anos. Portanto, há uma história familiar e uma relação construída com o consumidor e que se mantém ao longo dos anos. Nota-se que essa prática da informalidade persiste mesmo com a presença de entraves e se apresenta como uma alternativa e como possibilidade concreta de conquistar melhores condições econômicas e sociais para suas famílias.

A viabilidade, no caso das AFRIs, está na composição de matéria-prima e produtos que fazem parte dos arranjos produtivos sustentáveis. O que dá sustentabilidade, autonomia e viabilidade é o sistema de produção e o jeito de produzir. A gestão desse sistema, mesmo sendo mais complexa, é mantida sob controle da família e as estratégias adotadas têm a ver com o manejo do sistema produtivo e com as estratégias de reprodução das famílias. De certa forma, essas experiências informais de processamento de alimentos se caracterizam por sistemas de produção inclusivos em pequena escala, considerando que todos os entrevistados possuem atividades de produção primária e de processamento que envolve os membros da família.

É de conhecimento que o projeto de desenvolvimento rural adotado ao longo de décadas no Brasil, tem como principal objetivo a expansão do agronegócio. No entanto, esta opção tem implicado custos sociais e ambientais crescentes. Por outro lado, o avanço dos movimentos sociais no campo tem tornado cada vez mais evidente a necessidade de se elaborar uma estratégia de desenvolvimento que priorize as oportunidades de desenvolvimento social e não se restrinja a uma perspectiva estritamente econômica e setorial. Neste contexto das oportunidades de desenvolvimento social, talvez se possa ainda ter esperança de realização de ações que parecem estar longe de nossa capacidade de realização - as utopias.

Este artigo apresenta indicativos de que a produção na agricultura familiar e o processamento de alimentos não é uma transição que se encaminha para o consumismo, o individualismo e a dominação dos recursos naturais, ao contrário, esse modo de vida tem como fundamentos a solidariedade humana, a sensibilidade ambiental e a vida com qualidade. Parece-nos que esse deve ser o caminho a ser seguido como perspectiva futura de desenvolvimento humano sustentável e acreditar que é possível tornar utopias possíveis.

Há que se chamar a atenção para a necessidade de políticas públicas adequadas para dar conta dessas especificidades, já que em termos numéricos gerais o setor informal de processamento de alimentos é mais significativo, em praticamente todos os municípios do Estado.

\section{Referências}


ABRAMOVAY, R. et al. Juventude e agricultura familiar: desafios dos novos padrões sucessórios. Brasília: Unesco, $1998 . \quad$ Disponível em: < http://www.dominiopublico.gov.br/download/texto/ue000152.pdf >. Acesso em: 07 out. 2019.

ABRANDH. O direito humano à alimentação adequada e o sistema nacional de segurança alimentar e nutricional / organizadora, Marília Leão.. Módulo I - A Segurança Alimentar e Nutricional e o Direito Humano à Alimentação Adequada (DHAA). 2010. 53p. DF, 2013.

BIACHINI, G., N. A Política de Apoio às agroindústrias Familiares de Pequeno Porte de processamento Artesanal na Região da Quarta Colônia de Imigração Italiana do RS. Tese de Doutorado. Santa Cruz do Sul, 2015.

BRANDÃO, C. R. A comunidade tradicional. In: UDRY, C.; EIDT, J. S.; Editoras Técnicas. Conhecimento tradicional: conceitos e marco legal. Brasília: Embrapa, 2015.

BRASIL. Lei 9.712, de 20 de fevereiro de 1998, dispõe sobre o Sistema Unificado de Atenção à Sanidade Agropecuária, alterou a Lei 8.171, de 17 de janeiro de 1991. Regulamentação pelo Decreto $\mathrm{N}^{\circ}$ 5.741, de 30 de março de 2006. Disponível em: < https:/www.gov.br/agricultura/ptbr/assuntos/suasa/suasa >. Acesso em 08 jul. de 2019.

BRASIL. Lei $\mathrm{n}^{0}$ 8.629, de 25 de fevereiro de 1993. Dispões sobre a regulamentação dos dispositivos constitucionais relativos à reforma agrária. Disponível em: http://www.planalto.gov.br/ccivil 03/leis/18629.htm. Acesso em 11 de ago. de 2019.

DELGADO, N.G. Agronegócio e agricultura familiar no Brasil: desafios para a transformação democrática do meio rural. Novos Cadernos NAEA. v. 15, n. 1, p. 85-129, jun. 2012

EMBRAPA. Módulos Fiscais. 2012. Disponível em: < https://www.embrapa.br/codigo-florestal/areade-reserva-legal-arl/modulo-fiscal > Acesso em: 09 out. 2019.

EMATER/RS. Agroindústria Familiar. Disponível em: http://www.emater.tche.br/site/areatecnica/agregacao-de-valor/agroindustria-familiar. Acesso em: 07 out. 2019.

GAZOLLA, M. Instituições e economia dos custos de transação: aplicação de alguns elementos para a análise dos pequenos empreendimentos agroindustriais. REDES, Santa Cruz do Sul, v. 14, n. 3, p. $161-185$, set./dez. 2009.

GOODMAN, D. The quality "turn" and alternative food practices: reflections and agenda. Journalof Rural Studies, v. 19, p.1-7, 2003.

GUIMARÃES, G. M. A legislação Industrial e Sanitária dos Produtos de Origem Animal: o caso das Agroindústrias de Pequeno Porte. Santa Maria. UFSM. Dissertação (CPGExR), 2001.

IBGE. Censo agropecuário, 2017. Disponível em : https://www.ibge.gov.br/estatisticas Acesso: 09 de out.. 2019

KALNIN, J. L. Desenvolvimento local/regional focado na agroindústria familiar: experiências em Santa Catarina. Florianópolis: UFSC, 2004.

MINISTÉRIO DO DESENVOLVIMENTO SOCIAL E COMBATE À FOME - BNDES. Agricultura familiar. 2014. Disponível em: <http://www.mds.gov.br/falemds/perguntas-frequentes/bolsafamilia/programa-complementares/beneficiario/agricultura-familiar > Acesso em: 16 out. 2014.

MIOR, L.C. Agricultores familiares, agroindústrias e redes de desenvolvimento rural. Chapecó, Unochapecó, Editora Argos, 2005. 
PEREIRA, M., P.; BOTELHO, M., I., V. A Invisibilidade Social e Política doa agricultores Familiares e seus Reflexos nas Relações com o Estado. Revista Internacional Interdisciplinar INTERthesis, Florianópolis, v.14, n.2, p.113-131 Mai.-Ago. 2017.

PREFEITURA MUNICIPAL DE SANTA CRUZ DO SUL. Divisão Distrital 2018. Disponível em: <https://www.researchgate.net/figure/Figura-2-Mapa-de-localizacao-de-Santa-Cruz-do-SulOrganizacao-do-autores_fig1_304198962> Acesso em: 17 dez. 2019.

Relatório Final das Agroindústrias Familiares da Comissão de Agricultura, Pecuária e Cooperativismo da Assembleia Legislativa - RS. RDI 87/2017. Porto Alegre, novembro 2017.

RIO GRANDE DO SUL. Lei $\mathrm{n}^{0} 13.825$, de 4 de novembro de 2011. Regulamentada pelo Decreto $\mathrm{n}^{\circ}$ 49.340, de 05 de julho de 2012. Dispóes sobre o Sistema Unificado Estadual de Sanidade Agroindustrial Familiar, Artesanal e de Pequeno Porte. Disponível em: < https://www.agricultura.rs.gov.br > Acesso em 19 de set, 2019.

RIO GRANDE DO SUL, 2013. Programa de Agroindústria Familiar - PEAF. Secretaria de Desenvolvimento Rural, Pesca e Cooperativismo - SDR.

SANTOS, M., SILVEIRA, M. L. O Brasil: território e sociedade no início do século XXI. 5 ed. Rio de janeiro: Record, 2003.

SANTOS, Milton. A natureza do espaço. 4. ed. São Paulo: Edusp, 2004.

SCARABELOT, M.; SCHNEIDER, S. As Cadeias Agroalimentares Curtas e Desenvolvimento Local - Um Estudo de Caso no Município de Nova Veneza/SC. Volume 14 - Número 19 - Jan/Jun 2012 - pp. 101-130.

SCHNEIDER, S., GRISA, C. "Plantar pro gasto": a importância do autoconsumo entre famílias de agricultores do Rio Grande do Sul. Rev. Econ. Sociol. Rural v.46 n.2 Brasília Apr./June 2008.

SCHNEIDER, Sergio. 2010. Reflexões sobre Diversidade e Diversificação. Agricultura, Formas Familiares de Desenvolvimento Rural. RURIS, vol.4, nº 1, março 2010.

SCHUMPETER, J. A. (1911) Teoria do desenvolvimento econômico. In: Os economistas. Traduzido por Maria Sílvia Possas. São Paulo: Nova Cultural,1997.

SETTON, M. G. J. A teoria do habitus em Pierre Bourdieu: uma leitura contemporânea. Revista Brasileira de Educação. N. 20. Maio/Jun/Jul/Ago, 2002.

THEODORO, M. As bases da Política de apoio ao Setor Informal no Brasil. 2000. Disponível $\mathrm{em}:<$ http://www.ipea.gov.br/pub/td/td_2000/td_762.pdf>Acesso em: set. 2019. Acesso em: 24 out. 2019.

WEISHEIMER, N. Sobre a invisibilidade social das juventudes rurais. DESIDADES, n. 1, ano 1. Temas em destaque. 2013

WILKINSON, J.; MIOR, L.C. Setor informal, produção familiar e pequena agroindústria: interfaces. Estudos Sociedade e Agricultura. No 13, 1999. (p.29-45)

WINCKLER, M. BOUFLEUER, T. R. FERRETTI, F. DE SÁ, C. A. Idosos no meio rural: uma revisão integrativa. Estudos interdisciplinares sobre o envelhecimento, Porto Alegre, v. 21, n. 2, p. 173-194, 2016. 